\title{
RANCANG BANGUN SISTEM INFORMASI PENJUALAN KUE DAN ROTI BERBASIS WEB PADA YUKI BAKERY JAKARTA
}

\author{
Riswandi Ishak ${ }^{1}$, Handini Widyastuti ${ }^{2}$, Setiaji ${ }^{3}$ \\ ${ }^{1}$ AMIK BSI Jakarta \\ JI. R. S. Fatmawati No. 24, Pondok Labu, Jakarta Selatan \\ Email : riswandi.rik@bsi.ac.id \\ ${ }^{2}$ AMIK BSI Bekasi \\ Jl. Cut Mutiah Bekasi \\ Email : handini.hwy@bsi.ac.id \\ ${ }^{3}$ AMIK BSI Pontianak \\ Jl. Abdurahman Saleh No. A18, Pontianak \\ Email : setiaji.sej@bsi.ac.id
}

\begin{abstract}
ABSTRAK
Yuki Bakery merupakan toko yang bergerak dalam bidang penjualan Kue dan Roti yang berlokasi di Jalan Joglo Raya, Jakarta Barat. Sampai saat ini Yuki Bakery hanya menggunakan sistem sederhana dalam pemasaran informasi dan pencatatan, sehingga menimbulkan kelambatan dalam pemasaran informasi dan dalam pencatatan perhitungan penjualan. Berdasarkan permasalahan di atas penulis merancang dan membuat sistem informasi pada Yuki Bakery. Sistem informasi ini menerapkan waterfall model dalam pembangunannya, dan dibangun dengan bahasa pemrograman PHP dan menggunakan MySql. Perancangan program yang akan dikerjakan, dengan acuan program yang dibuat harus user friendly dan dengan menggunakan metode UML (unifed Modeling Language) dengan membuat Use Case Diagram, Class Diagram dan Sequence Diagram, desain database dan ERD. Sistem informasi ini mampu memperkenalkan dan menjual secara online serta menghasilkan informasi produkproduk yang dijual dan laporan penjualan bagi pemilik toko dengan menggunakan sebuah website. Dengan adanya website pemasaran ini dapat membantu perusahaan dalam meningkatkan pelayanan dan penjualan di berbagai wilayah baik dalam kota maupun luar kota.
\end{abstract}

Kata kunci : Sistem Informasi, Website, Waterfall

\begin{abstract}
Yuki Bakery is a shop engaged in the sale of Cakes and Breads at Jalan Joglo Raya, West Jakarta. Until now Yuki Bakery uses only a simple system in marketing information and recordings, thus causing delays in information marketing and in recording sales calculations. Based on the above questions the author of information and information about Yuki Bakery. This information system applies the waterfall model in its development, and is built with PHP programming language and uses MySql. The design of the program will be done, with the program chosen to be user friendly and by using UML (Unifed Modeling Language) method by making Use Case Diagram, Class Diagram and Sequence Diagram, database design and ERD. This information system is able to introduce and sell online and generate information about sales of products and sales reports for shop owners using the website. With the existence of this marketing site can help companies in improving services and sales in various areas both within the city and outside the city.
\end{abstract}

Keyword : Information System, Website, Waterfall 
JURNAL SWABUMI, Vol.6 No.1 Maret 2018, pp. 27 34

ISSN: 2355-990X

\section{Pendahuluan}

Yuki Bakery merupakan toko yang bergerak dalam bidang penjualan Kue dan Roti yang berlokasi di Jalan Joglo Raya, Jakarta Barat. Kue dan Roti ini mempunyai mutu yang tinggi dan kualitasnya sudah tidak diragukan lagi. Dalam segi penjualan Yuki Bakery juga mengalami peningkatan signifikan. Ini dapat dilihat dari semakin banyaknya jumlah para pembeli pada Yuki Bakery.

Dengan semakin berkembangnya tingkat penjualan yang ada, Yuki Bakery ingin memberikan pelayanan yang memuaskan kepada pelanggannya. Untuk itu perlu suatu dukungan sistem yang terkomputerisasi, yang dapat membantu pemilik dan karyawan dalam proses penjualan demi kemajuan Yuki Bakery dimasa yang akan datang agar berkembang menjadi perusahaan dagang yang lebih besar. Namun, seiring dengan meningkatnya permintaan produk oleh konsumen dan perkembangan teknologi dewasa ini, maka persaingan dalam perdagangan semakin ketat dan usaha yang bisa dilakukan salah satunya dengan cara promosi dan pemberian informasi yang cepat dan akurat. Namun dengan sistem yang berjalan sekarang, terdapat beberapa permasalahan seperti belum maksimalnya dalam penyampaian informasi produk yang ditawarkan dikarenakan kurangnya media penyampaian informasi untuk promosi, Proses transaksi jual-beli berjalan lambat dan terlalu memerlukan waktu yang banyak, dimana pelanggan yang tertarik untuk membeli produk yang diinginkan harus datang langsung ke toko.

Menurut Rejeki dkk

(2011:1) menyimpulkan bahwa:

Manfaat dari penerapan penggunaan Ecommerce, akan memberikan gambaran tentang bagaimana teknik sistem penjualan yang dibutuhkan dalam menghadapi persaingan perusahaan di era globalisasi saat ini. Diharapkan mampu memudahkan bagi penjual dalam membuat laporan rekapitulasi penjualan sehingga laporan dapat dihasilkan dengan cepat dan akurat.

Hal inilah yang mungkin sekiranya perlu diubah dalam mempromosikan produk agar lebih terjangkau lagi oleh pelanggan yang menginginkan kemudahan dalam membeli produk. Maka perlu adanya suatu sistem penjualan berbasis web

(e-commerce) yang lebih dinamis untuk memudahkan promosi barang dan mempercepat proses transaksi jual-beli produk. Selain itu dapat membantu pelanggan untuk mendapatkan informasi produk dan memesan produk tanpa harus datang langsung ke toko. Dengan menggunakan sarana ini maka semua keterbatasan sarana, jarak dan waktu dapat teratasi dengan mudah. Sehingga dapat memberikan kenyamanan bagi pelanggan dalam berbelanja.

\section{Permasalahan}

Permasalahan yang dihadapi saat ini adalah:

1. Belum maksimalnya dalam penyampaian informasi produk yang ditawarkan dikarenakan kurangnya media penyampaian informasi untuk promosi.

2. Proses transaksi jual-beli berjalan lambat dan terlalu memerlukan waktu yang banyak, dimana pelanggan yang tertarik untuk membeli produk yang diinginkan, harus datang langsung ke toko.

3. Laporan stok barang yang masih manual kurang mendukung prosedur penjualan.

\section{Tujuan}

Berdasarkan permasalahan yang dihadapi, adapun maksud dan tujuan tersebut adalah sebagai berikut:

1. Memberikan solusi kepada pihak Yuki Bakery yang selama ini masih belum menggunakan teknologi informasi dalam menyampaikan informasi dan pemasaran mengenai produk yang tersedia, khususnya menggunakan media internet.

2. Meningkatkan pelayanan melalui penerapan e-commerce pada Yuki Bakery agar dapat memberikan kemudahan transaksi online kepada para konsumennya.

3. Menghasilkan laporan penjualan yang kebih spesifik dengan akurat dan tepat waktu.

4. Membantu pihak Yuki Bakery dalam mempromosikan produk sehingga dapat memperluas jangkauan pemasaran.

\section{Metode Penelitian}

2.1. Teknik Pengumpulan Data

a. Observasi

Mengadakan pengamatan langsung kelapangan terutama pada bagian penjualan untuk mengamati keadaan sebenarnya dari 
obyek yang akan diteliti guna mendapat memperoleh data sesungguhnya dari perusahaan tersebut. Dengan demikian didapat kejelasan terhadap proses-proses yang sedang terjadi seperti orang-orang yang terlibat didalam sistem tersebut, dokumen-dokumen yang digunakan dalam pencatatan data-datanya, data-data pendukung lainnya, dokumen-dokumen yang dihasilkan dari pengolahan data tersebut.

\section{b. Wawancara}

Wawancara secara langsung kepada Bapak Odih Irawan selaku Pemilik sekaligus pimpinan pada Yuki Bakery. Adapun hasil wawancara adalah mengenai sejarah perusahaan, struktur organisasi beserta fungsinya, prosedur penjualan dan pemasarannya dan laporan penjualan.

\section{c. Studi Pustaka}

Melakukan pengumpulan data melalui beberapa buku dan jurnal sebagai referensi dan juga sumber-sumber lainnya.

\subsection{Model Pengembangan Sistem}

1. Analisa Kebutuhan Sistem

Analisis data dilakukan untuk menentukan kebutuhan software untuk pendukung program aplikasi yaitu dengan seperti adanya login user yang berguna untuk masuk ke website tersebut dengan status dia sudah mendaftar di website tersebut, shopping cart sebagai penampung data data barang yang akan dibeli oleh konsumen, category sebagai info tentang produk yang dijual.

\section{Desain}

Tahapan ini menjelaskan mengenai perancangan program yang akan dikerjakan, dengan acuan program yang dibuat harus user friendly dan dengan menggunakan metode UML (Unifed Modeling Language) dengan membuat Use Case Diagram, Class Diagram dan Sequence Diagram, desain database dan ERD.

\section{Code Generation}

Code Generation adalah proses dimana compiler's generator kode mengkonversi beberapa perwakilan intermedit dari kode sumber menjadi bentuk (misalnya, kode mesin ) yang dapat dengan mudah dieksekusi oleh mesin. Dan adapun bahasa pemrograman yang digunakan penulis yaitu menggunakan PHP dan databasenya menggunakan MySQL.

\section{Testing}

Tiap aktivitas yang digunakan untuk dapat melakukan evaluasi suatu atribut atau kemampuan dari program atau sistem dan menentukan apakah telah memenuhi kebutuhan atau hasil yang diharapkan, Black Box testing adalah cara melakukan test pengujiannya..

\section{Support}

Dalam pembuatan penelitian ini, hardware pendukung yang digunakan yaitu sebuah laptop Processor Intel(R) Core(TM) i3-2350M CPU @2.30 GHz(4 Cpus), 2.3 GHzAMD Installed memory (RAM) 4096MB RAM, Hardisk 500GB.

\section{Hasil dan Pembahasan \\ 3.1. Proses Bisnis Sistem}

Dalam kegiatan penjualan toko Yuki Bakery, diawali ketika konsumen datang langsung ke toko tersebut untuk membeli kue atau roti. Setelah konsumen mendapat kue atau roti yang diinginkan dan setelah konsumen mengetahui harga barang, jika konsumen merasa tidak cocok dengan harga atau barang yang telah dipilih konsumen bisa memilih kembali barang yang diinginkan dan jika konsumen merasa sudah cocok dengan harga atau barang yang dipilih, konsumen bisa langsung menyerahkan barang yang dipilih ke bagian penjualan untuk dibuatkan struk pembayaran. Setelah konsumen menerima struk pembayaran, konsumen bisa langsung menerima barang belanjaan yang telah dibeli secara cash dan barang pun diterima.

Untuk penggambarannya dapat dilihat pada activity diagram sebagai berikut: 


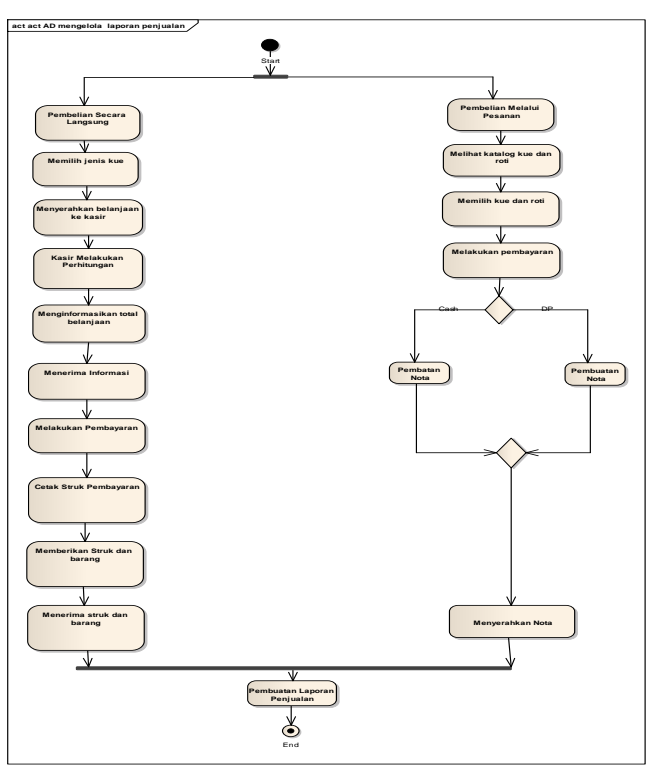

Gambar 1.

Activity Diagram Penjualan Kue

\subsection{Analisa Kebutuhan Software}

\subsubsection{Tahapan Analisis}

Sistem penjualan secara online berbasis web dimana penjual dan pembeli tidak bertatap muka secara langsung. Calon pembeli melakukan pembelian melalui media browser. Berikut ini spesifikasi kebutuhan (system requirement) dari sistem e-commerce.

\subsubsection{Use Case Diagram}

Use Case mendeskripsikan sebuah interaksi antara satu atau lebih actor dengan sistem informasi yang akan dibuat. Setiap use case dapat dideskripsikan dalam dokumen yang disebut dengan dokumen flow of event. Dokumen ini mendefinisikan apa yang harus didefinisikan oleh sistem ketika actor mengaktifkan use case. Struktur dokumen use case ini bermacam-macam, tetapi umunya deskripsi ini mengandung:

1. Brief Description (deskripsi singkat)

2. Actor yang terlibat

3. Precondition yang penting bagi use case untuk memulai

4. Deskripsi rinci dari aliran kejadian yang mencangkup main flow, dari kejadian ini bisa dirinci menjadi sub flow dan alternatif flow.

Berikut ini merupakan use case diagram dari sistem penjualan kue dan roti yang diusulkan:

\section{Use Case Diagram Belanja Online Halaman User}

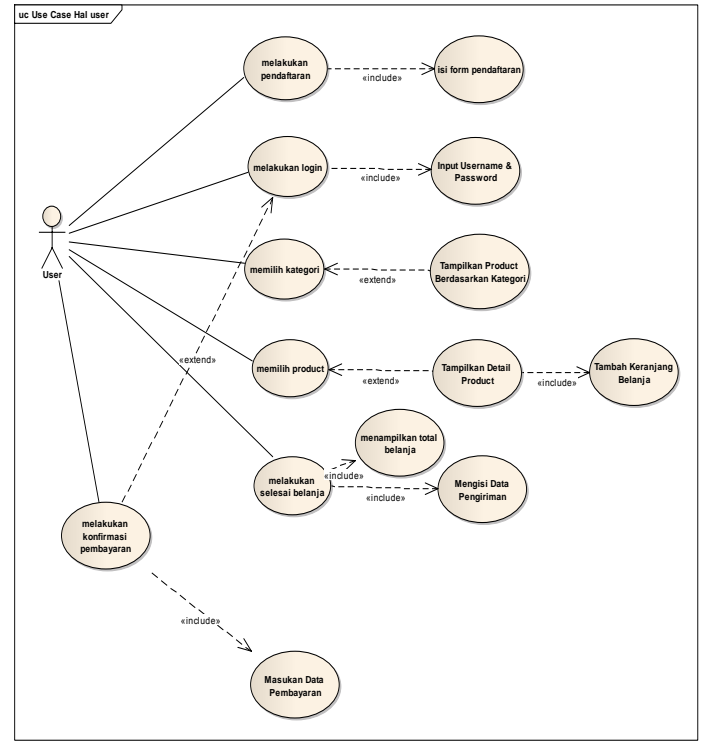

Gambar 2.

Use Case Diagram Halaman User

Tabel 1.

Deskripsi Use Case Diagram Pendaftaran

\begin{tabular}{|c|c|}
\hline $\begin{array}{ll}\text { Use } & \text { Case } \\
\text { Name } & \\
\end{array}$ & Pendaftaran \\
\hline Requirements & A1 \\
\hline Goal & User harus melakukan pendaftaran \\
\hline $\begin{array}{l}\text { Pre- } \\
\text { conditions }\end{array}$ & $\begin{array}{l}\text { User mengetahui situs dari sistem } \\
\text { belanja online }\end{array}$ \\
\hline $\begin{array}{l}\text { Post } \\
\text { conditions }\end{array}$ & User harus mengisi form pendaftaran \\
\hline $\begin{array}{l}\text { Failed end } \\
\text { conditions }\end{array}$ & $\begin{array}{l}\text { User membatalkan pendaftaran, } \\
\text { kemungkinan user ngin melihat-lihat } \\
\text { katalog saja }\end{array}$ \\
\hline $\begin{array}{l}\text { Primary } \\
\text { Actors }\end{array}$ & User \\
\hline $\begin{array}{l}\text { Main Flow / } \\
\text { Basic path }\end{array}$ & $\begin{array}{l}\text { 1. User harus daftar sebagai } \\
\text { member terlebih dahulu } \\
\text { 2. User harus melengkapi form } \\
\text { pendaftaran }\end{array}$ \\
\hline Invariant & - \\
\hline
\end{tabular}

Tabel 2.

Deskripsi Use Case Diagram Login

\begin{tabular}{|l|l|}
\hline $\begin{array}{l}\text { Use Case } \\
\text { Name }\end{array}$ & Melakukan Login \\
\hline Requirements & A2 \\
\hline Goal & $\begin{array}{l}\text { User dapat melakukan pembelian } \\
\text { secara online via web tetapi harus } \\
\text { melakukan login terlebih dahulu }\end{array}$ \\
\hline Pre-conditions & User telah login \\
\hline Post conditions & User dapat melakukan pembelian \\
\hline $\begin{array}{l}\text { Failed end } \\
\text { conditions }\end{array}$ & Gagal login \\
\hline Primary Actors & User \\
\hline $\begin{array}{l}\text { Main Flow / } \\
\text { Basic path }\end{array}$ & $\begin{array}{l}\text { 1. User dapat login dengan } \\
\text { account yang telah dibuat } \\
\text { Jika username dan passsword } \\
\text { yang dimasukkan sudah benar } \\
\text { maka akan tampil menu utama }\end{array}$ \\
\hline
\end{tabular}




\begin{tabular}{|l|l|}
\hline Invariant & - \\
\hline & \\
\hline
\end{tabular}

Tabel 3.

Deskripsi Use Case Diagram Kategori

\begin{tabular}{|l|l|}
\hline $\begin{array}{l}\text { Use Case } \\
\text { Name }\end{array}$ & Kategori \\
\hline Requirements & A3 \\
\hline Goal & User dapat memilih kategori \\
\hline Pre-conditions & $\begin{array}{l}\text { User bisa melihat terlebih dahulu } \\
\text { kategori sebelum mendaftar } \\
\text { sebagai member }\end{array}$ \\
\hline Post conditions & $\begin{array}{l}\text { User bisa memiih product yang } \\
\text { diinginkan sesuai dengan kategori }\end{array}$ \\
\hline $\begin{array}{l}\text { Failed end } \\
\text { conditions }\end{array}$ & $\begin{array}{l}\text { Memungkinkan user hanya melihat } \\
\text { produk berdasarkan kategori saja } \\
\text { tanpa melanjutkan pembelian }\end{array}$ \\
\hline Primary Actors & User \\
\hline $\begin{array}{l}\text { Main Flow / } \\
\text { Basic path }\end{array}$ & $\begin{array}{l}\text { User bisa memilih barang } \\
\text { berdasarkan kategori setelah login }\end{array}$ \\
\hline Invariant & - \\
\hline $\begin{array}{l}\text { Use Case } \\
\text { Name Kategori }\end{array}$ & \multicolumn{2}{|c|}{} \\
\hline
\end{tabular}

Tabel 4.

\section{Deskripsi Use Case Diagram Memilih Product}

\begin{tabular}{|l|l|}
\hline $\begin{array}{l}\text { Use Case } \\
\text { Name }\end{array}$ & Memilih Product \\
\hline Requirements & A4 \\
\hline Goal & $\begin{array}{l}\text { User dapat memilih product sesuai } \\
\text { dengan yang diinginkan }\end{array}$ \\
\hline $\begin{array}{l}\text { Pre- } \\
\text { conditions }\end{array}$ & User harus login terlebih dahulu \\
\hline $\begin{array}{l}\text { Post } \\
\text { conditions }\end{array}$ & $\begin{array}{l}\text { User bisa memilih product sesuai } \\
\text { kategori }\end{array}$ \\
\hline $\begin{array}{l}\text { Failed end } \\
\text { conditions }\end{array}$ & $\begin{array}{l}\text { User bisa membatalkan product } \\
\text { yang tidak jadi dibeli }\end{array}$ \\
\hline $\begin{array}{l}\text { Primary } \\
\text { Actors }\end{array}$ & User \\
\hline $\begin{array}{l}\text { Main Flow } \\
\text { Basic path }\end{array}$ & $\begin{array}{l}\text { User memilih barang yang } \\
\text { akan dibeli } \\
\text { Product yang telah dipilih } \\
\text { dapat ditambahkan ke } \\
\text { keranjang belanja }\end{array}$ \\
\hline Invariant & - \\
\hline $\begin{array}{l}\text { Use Case } \\
\text { Name }\end{array}$ & Memilih Product \\
\hline
\end{tabular}

Tabel 5.

Deskripsi Use Case Diagram Selesai Belanja

\begin{tabular}{|l|l|}
\hline $\begin{array}{l}\text { Use Case } \\
\text { Name }\end{array}$ & Selesai belanja \\
\hline Requirements & A5 \\
\hline Goal & $\begin{array}{l}\text { User dapat melakukan pembelian } \\
\text { online via web }\end{array}$ \\
\hline $\begin{array}{l}\text { Pre- } \\
\text { conditions }\end{array}$ & User telah memilih barang \\
\hline $\begin{array}{l}\text { Post } \\
\text { conditions }\end{array}$ & System menyimpan total belanjaan \\
\hline Failed end & User membatalkan selesai belanja. \\
\hline
\end{tabular}

\begin{tabular}{|l|l|}
\hline conditions & $\begin{array}{l}\text { Kemungkinan barang, aservingin } \\
\text { menambah atau } \\
\text { membatalkan pembelian. }\end{array}$ \\
\hline $\begin{array}{l}\text { Primary } \\
\text { Actors }\end{array}$ & User \\
\hline $\begin{array}{l}\text { Main Flow / } \\
\text { Basic path }\end{array}$ & $\begin{array}{l}\text { 1. User memilih icon checkout. } \\
\text { 2. System menampilkan rincian } \\
\text { belanja. } \\
\text { 3. User menyetujui dan } \\
\text { melanjutkan. }\end{array}$ \\
\hline Invariant & - \\
\hline $\begin{array}{l}\text { Use Case } \\
\text { Name Selesai belanja }\end{array}$ & Pane \\
\hline
\end{tabular}

Tabel 6.

Deskripsi Use Case Diagram Konfirmasi Pembayaran

\begin{tabular}{|l|l|}
\hline $\begin{array}{l}\text { Use Case } \\
\text { Name }\end{array}$ & Konfirmasi Pembayaran \\
\hline Requirements & A6 \\
\hline Goal & Melakukan konfirmasi pembayaran \\
\hline $\begin{array}{l}\text { Pre- } \\
\text { conditions }\end{array}$ & Mengupload data pembayaran \\
\hline $\begin{array}{l}\text { Post } \\
\text { conditions }\end{array}$ & Data pembayaran tersimpan \\
\hline $\begin{array}{l}\text { Failed end } \\
\text { conditions }\end{array}$ & Gagal mengupload data \\
\hline $\begin{array}{l}\text { Primary } \\
\text { Actors }\end{array}$ & User \\
\hline $\begin{array}{l}\text { Main Flow / } \\
\text { Basic path }\end{array}$ & \multicolumn{2}{|c|}{$\begin{array}{l}\text { User harus login terlebih } \\
\text { dahulu } \\
\text { User mengupload data } \\
\text { pembayaran }\end{array}$} \\
\hline $\begin{array}{l}\text { Invariant } \\
\text { Use Case } \\
\text { Name }\end{array}$ & Konfirmasi Pembayaran \\
\hline
\end{tabular}

\section{Use Case Diagram Belanja Online Halaman Administrator}

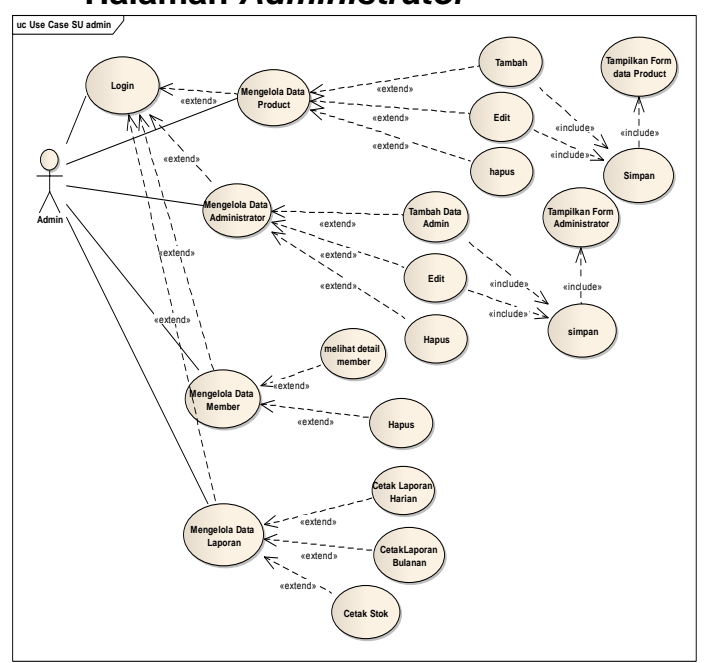

Gambar 3.

Use Case Diagram Belanja Online Halaman Administrator

Tabel 7. 
Deskripsi Use Case Diagram Mengelola Data Product

\begin{tabular}{|l|l|}
\hline $\begin{array}{l}\text { Use Case } \\
\text { Name }\end{array}$ & Mengelola data Product \\
\hline Requirements & B1 \\
\hline Goal & $\begin{array}{l}\text { Admin dapat menambah, } \\
\text { mengedit dan menghapus data } \\
\text { produk }\end{array}$ \\
\hline $\begin{array}{l}\text { Pre- } \\
\text { conditions }\end{array}$ & Admin telah login \\
\hline $\begin{array}{l}\text { Post } \\
\text { conditions }\end{array}$ & $\begin{array}{l}\text { Data } \\
\text { tersimpan,terupdate, } \\
\text { terhapus }\end{array}$ \\
\hline $\begin{array}{l}\text { Failed end } \\
\text { conditions }\end{array}$ & $\begin{array}{l}\text { Gagal menyimpan, mengupdate, } \\
\text { atau menghapus data produk }\end{array}$ \\
\hline $\begin{array}{l}\text { Primary } \\
\text { Actors }\end{array}$ & Administrator \\
\hline $\begin{array}{l}\text { Main Flow } \\
\text { Basic path }\end{array}$ & $\begin{array}{l}\text { 1. Admin melihat daftar produk } \\
\text { 2. Admin menambah produk }\end{array}$ \\
\hline $\begin{array}{l}\text { Alternate } \\
\text { Flow/ Admin menyimpan produk } \\
\text { Invariant 1 }\end{array}$ & Admin mengedit data produk \\
\hline
\end{tabular}

Tabel 8.

Deskripsi Use Case Diagram Mengelola Data Administrator

\begin{tabular}{|l|l|}
\hline $\begin{array}{l}\text { Use Case } \\
\text { Name }\end{array}$ & Mengelola Data Admin \\
\hline Requirements & B3 \\
\hline Goal & $\begin{array}{l}\text { Admin dapat melihat dan } \\
\text { mencetak laporan penjualan }\end{array}$ \\
\hline $\begin{array}{l}\text { Pre- } \\
\text { conditions }\end{array}$ & Admin telah login \\
\hline $\begin{array}{l}\text { Post } \\
\text { conditions }\end{array}$ & Data anggota terhapus \\
\hline $\begin{array}{l}\text { Failed end } \\
\text { conditions }\end{array}$ & Gagal menghapus data anggota \\
\hline $\begin{array}{l}\text { Primary } \\
\text { Actors }\end{array}$ & Administrator \\
\hline $\begin{array}{l}\text { Main Flow } \\
\text { Basic path }\end{array}$ & $\begin{array}{l}\text { 1. Admin melihat daftar } \\
\text { anggota } \\
2 . \\
\text { data anggota }\end{array}$ \\
\hline $\begin{array}{l}\text { Alternate } \\
\text { Flow/ } \\
\text { Invariant 1 }\end{array}$ & \multicolumn{2}{|c|}{ menghapus } \\
\hline
\end{tabular}

Tabel 9.

Deskripsi Use Case Diagram Mengelola Laporan Penjualan

\begin{tabular}{|l|l|}
\hline $\begin{array}{l}\text { Use Case } \\
\text { Name }\end{array}$ & Mengelola Laporan Penjualan \\
\hline Requirements & B4 \\
\hline Goal & $\begin{array}{l}\text { Admin dapat melihat dan } \\
\text { mencetak laporan penjualan }\end{array}$ \\
\hline $\begin{array}{l}\text { Pre- } \\
\text { conditions }\end{array}$ & Admin telah login \\
\hline $\begin{array}{l}\text { Post } \\
\text { conditions }\end{array}$ & $\begin{array}{l}\text { Laporan telah tercetak atau } \\
\text { tersimpan }\end{array}$ \\
\hline $\begin{array}{l}\text { Failed end } \\
\text { conditions }\end{array}$ & $\begin{array}{l}\text { Gagal menyimpan atau } \\
\text { mencetak laporan penjualan }\end{array}$ \\
\hline
\end{tabular}

\begin{tabular}{|l|l|}
\hline $\begin{array}{l}\text { Primary } \\
\text { Actors }\end{array}$ & Administrator \\
\hline $\begin{array}{l}\text { Main Flow / } \\
\text { Basic path }\end{array}$ & $\begin{array}{l}\text { Admin menyimpan atau } \\
\text { mencetak laporn penjualan }\end{array}$ \\
\hline $\begin{array}{l}\text { Alternate } \\
\text { Flow/ } \\
\text { Invariant 1 }\end{array}$ & $\begin{array}{l}\text { Admin menyimpan atau } \\
\text { mencetak laporan penjualan }\end{array}$ \\
\hline
\end{tabular}

\subsubsection{Activity Diagram}

Berikut merupakan activity diagram yang diusulkan kepada Yuki Bakery Jakarta.

1. Activity Diagram Belanja Online Halaman User

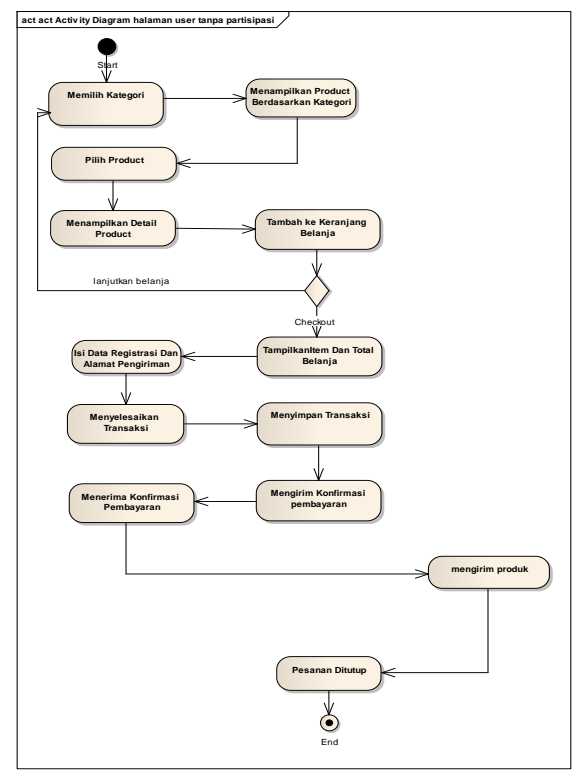

Gambar 3. Activity Diagram Belanja Online Halaman User

2. Activity Diagram Mengelola Data Barang

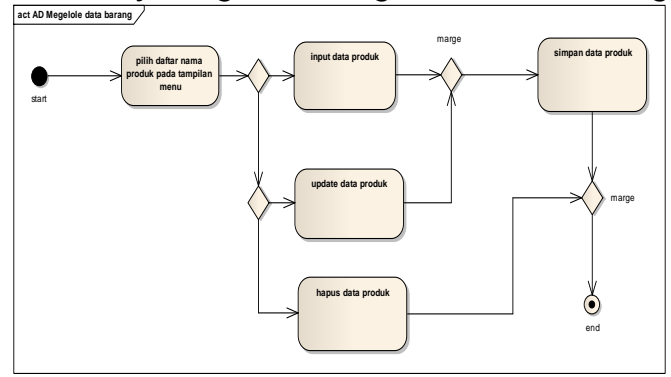

Gambar 4. Activity Diagram Mengelola Data Barang

3. Activity Diagram Mengelola Laporan Penjualan 


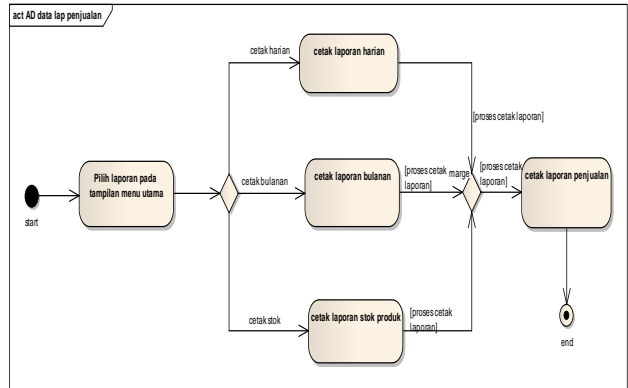

Gambar 5. Activity Diagram Mengelola Laporan Penjualan

4. Activity Diagram Mengelola Data Admin

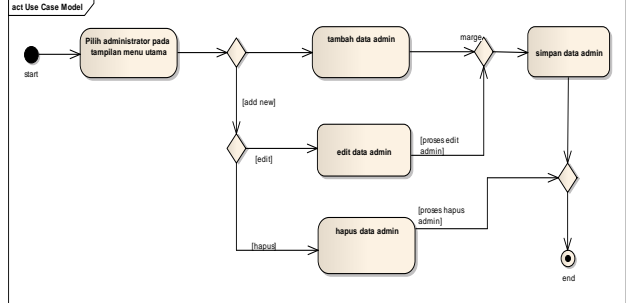

Gambar 6. Activity Diagram Mengelola Data Admin

5. Activity Diagram Mengelola Data Member

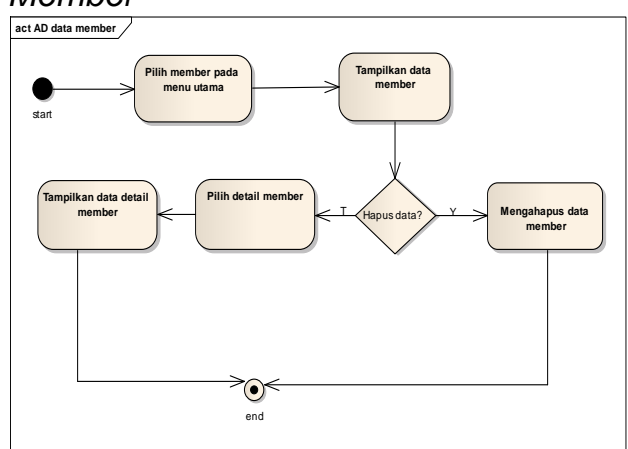

Gambar 7. Activity Diagram Mengelola Data Member

\subsection{Desain}

Tahapan ini menjelaskan tentang desain database, desain software architecture, dan desain interface yang dibuat.

3.3.1. Database

1. Entity Relationship Diagram

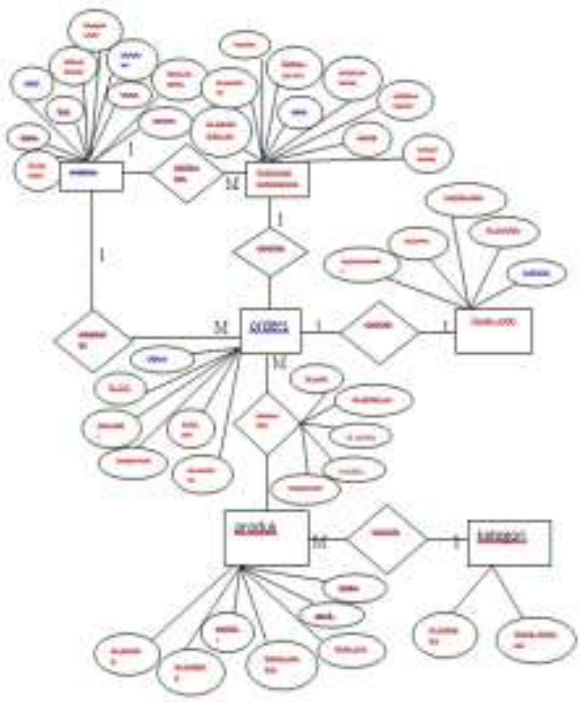

Gambar 8. Entity Relationship Diagram

2. Logical Record Structure

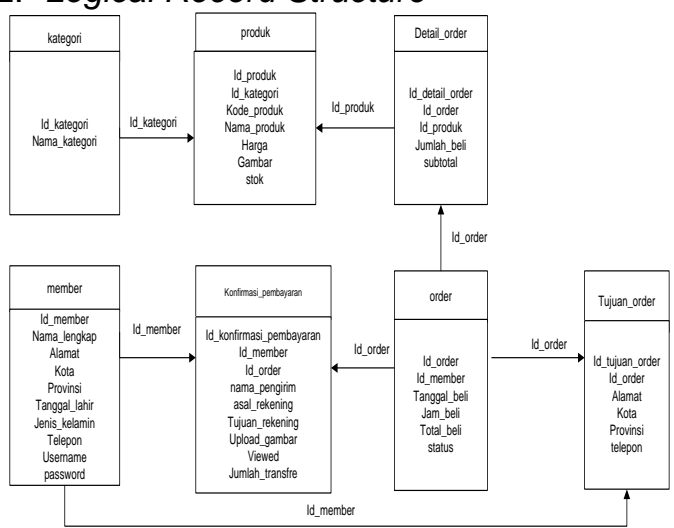

Gambar 9. Logical Record Structure

\section{Kesimpulan}

Kesimpulan yang diperoleh dari penelitian ini diantaranya Penggunaan komputerisasi mempercepat dalam proses akuntansi perusahaan. Penggunaan teknologi komputerisasi membantu dalam menghasilkan keputusan-keputusan yang akurat dan cepat, sehingga pelayanan terhadap seluruh pelanggan dapat meningkat dan semakin membaik. Sistem penjualan tunai pada Yuki Bakery yang terkomputerisasi akan memudahkan pekerjaan dan dapat meningkatkan kelancaran proses pelayanan penjualan. Dengan adanya website pemasaran ini diharapkan dapat membantu perusahaan dalam meningkatkan pelayanan dan penjualan di berbagai wilayah baik dalam kota maupun luar kota. 
Sedangkan pada pengelolahan datanya antara lain menambah data, menyimpan data, mengubah data, membatalkan data, menghapus data, sampai dengan pencetakan laporan.

Berdasarkan pengalaman yang didapat selama menjalankan riset pada Yuki Bakery, penulis mempunyai saran yang mungkin bermanfaat bagi perkembangan dan kemajuan perusahaan adalah sebagai berikut:

1. Hendaknya penggunaan teknologi komputerisasi lebih diterapkan dan ditingkatkan, dimana bermanfaat dalam pengolahan data, khususnya dalam sistem penjualan tunai sehingga dapat berjalan efektif dan efisien.

2. Penggunaan tekonologi komputerisasi menciptakan sumber daya manusia yang bermutu dan berkualitas dalam bidangnya.

3. Bukti-bukti pendukung hendaknya didokumentasikan dengan baik, sehingga tidak mengalami kesuliatan jika dibutuhkan (Back Up data)

4. Memberikan pelatihan atau training kepada karyawan untuk memperkenalkan dan membantu mereka terhadap sistem yang baru.

5. Pengawasan secara rutin dalam perawatan atau pemeliharaan sistem.

\section{Referensi}

Frieyadi. 2007. Modul Perancanagan Basis Data. Jakarta: Bina Sarana Informatika.

Jogiyanto, HM. 2005. Analisis dan Desaign Sistem Informasi : Pendekatan Teori Terstruktur dan Praktek Aplikasi Bisnis. Yogyakarta: Andi

Jogiyanto ,2005.Analisis dan Desain Sistem Informasi Edisi Ketua, Yogyakarta:Andi Offset.

Nugroho, Adi. 2010. Rekayasa Perangkat Lunak Berbasis Objek dengan Metode USDP. Yogyakarta: Andi Offset.

Sibero, Alexander F.K. 2011, Kitab Suci Web Programming. Yogyakarta: MediaKom.
Siska Wahyu Kartikasari.2012. Sistem Informasi Penjualan Berbasis Web Pada Toko Butik Podomoro. ISSN : 2302-1136(print) - 20880154(online).

Rejeki, Rara Sri Artati, Agus Prasetyo Utomo dan Stefiana Sri Susanti. 2011. Perancangan dan Pengaplikasian Sistem Penjualan pada "Distro Smith" Berbasis Ecommerce. ISSN: 0854-9524. Semarang: Jurnal Teknologi Informasi DINAMIK Volume 16, No.1, Juli 2011: 150-159. Diambil dari:

http://www.unisbank.ac.id/ojs/index. php/tti1/article/download/463/32.(25 November 2013)

Rudy, Suyan alias Wati, Reinaldi, Natalini.2008. Analisis dan Perancangan Sistem Ecommerce (studi kasus :PT. Istana Romantik Dekorindo). ISSN: 1907-1522. Diambil dari http://journal.uii.ac.id/index.php/Snat i/article/view/564.(25 November 2013)

Zulkifli, Alamsyah. 2005. Manajemen Informasi. Jakarta: Gramedia Pustaka Utama 